\title{
Production and Characterization of Porous Fibroin Scaffolds for Regenerative Medical Application
}

\author{
ALEXANDER KOPP ${ }^{1}$, RALF SMEETS ${ }^{2,3}$, MARTIN GOSAU ${ }^{2}$, REINHARD E. FRIEDRICH ${ }^{2}$, \\ SANDRA FUEST ${ }^{1}$, MEHDI BEHBAHANI ${ }^{4}$, MIKE BARBECK ${ }^{2,3}$, \\ RICO RUTKOWSKI ${ }^{2}$, SIMON BURG $^{2}$, LAN KLUWE $^{2,3}$ and ANDERS HENNINGSEN $2,3,5$ \\ ${ }^{1}$ Fibrothelium GmbH, Aachen, Germany; \\ ${ }^{2}$ Department of Oral and Maxillofacial Surgery, \\ University Medical Center Hamburg-Eppendorf, Hamburg, Germany; \\ ${ }^{3}$ Department of Oral and Maxillofacial Surgery, Division of Regenerative Orofacial Medicine, \\ University Medical Center Hamburg-Eppendorf, Hamburg, Germany; \\ ${ }^{4}$ University of Applied Sciences Aachen, Campus Jülich, Jülich, Germany; \\ ${ }^{5}$ Department of Oral and Maxillofacial Surgery, German Armed Forces Hospital, Hamburg, Germany
}

\begin{abstract}
Background/Aim: Silk is a natural biomaterial with several superior features for applications in regenerative medicine. In the present study an optimized process for manufacturing porous scaffolds out of the silk protein fibroin was developed. Materials and Methods: The silk protein fibroin was dissolved in Ajisawa's reagent and the resulting fibroin solution was used to produce scaffolds by means of freeze-thawing cycling. Porosity, pressure and stab resistance as well as degradation behavior were assessed in order to characterize the physical properties of the resulting scaffolds. Results: The resulting sponge-like fibroin scaffolds were highly porous while the porosity correlated inversely with the concentration of the starting fibroin solution. Increased initial fibroin concentrations of the scaffolds resulted in increased compressive and cannulation resistance. The majority of the fibroin scaffolds were digested by $1 \mathrm{mg} / \mathrm{ml}$ protease XIV in 3 weeks, indicating their biodegradability. Conclusion: The production of scaffolds made of varying fibroin concentrations by means of freeze-thawing, following dissolution using Ajisawa's reagent, provides a simple and straightforward strategy for adjusting the physical and chemical properties of fibroin scaffolds for various medical applications.
\end{abstract}

This article is freely accessible online.

Correspondence to: Anders Henningsen, Department of Oral and Maxillofacial Surgery, German Armed Forces Hospital, Lesserstrasse 180, 22049 Hamburg, Germany. Tel: +49 17660831622, e-mail: a.henningsen@uke.de

Key Words: Silk, fibroins, biomaterials, regeneration.
Silk is a promising biomaterial in tissue engineering and regenerative medicine. Its advantageous features include high biocompatibility, simple biochemical composition, smooth surface, mechanical strength and controllable degradation (1, 2 ). Silk can be manufactured into various forms and structures according to the application demands and therefore provides a favorable basic material in reconstructive medicine $(3,4)$. Mainly composed of fibroin $(70-80 \%)$ and sericin $(20-$ $30 \%$ ), silk is produced by the silkworm bombyx mori to form cocoons (5). The silk fibers are made of fibroins which are bundled by sericin. Solid silk can be brought into solution by means of removing sericin using acidic or alkaline solutions at a high temperature and subsequently dissolving the fibroin fiber in acidic or highly concentrated ion solutions (6-8). An alternative to the conventional concentrated and highly toxic lithium bromide solution is Ajisawa's reagent composed of $\mathrm{CaCl}_{2}-\mathrm{EtOH}-\mathrm{H}_{2} \mathrm{O}$, which is inexpensive, simple and much safer (9). The dissolved fibroin can be further processed into various types of materials for medical applications including membranes, thin films, hydrogel, fiber, matrix and sponges (10-12). For example, tube-shaped fibroin sponges held by fibroin membranes can serve as scaffolds for stem cells to differentiate into adipocytes (13). Sponges made of fibroin may provide an attractive alternative to conventional materials, like xenogenous collagen for hemostasis after tooth extraction (14).

So far, fibroin scaffolds have only been produced from fibroin solutions obtained using highly concentrated lithium bromide solutions or formic acid. The present study aimed to establish and optimize a process for producing porous sponge-like scaffolds using the less expensive and safer Ajisawa's reagent. The resulting scaffolds were characterized for their structural, mechanical and degradation properties. 
In addition, the effect of concentration of the initial fibroin solution on the properties of the scaffolds was evaluated.

\section{Materials and Methods}

Dissolution of fibroin and production of scaffolds. Silk cocoons (Source: Cantiere della provvidenza, Belluno, Italy) were used for fibroin extraction. Forty-five g of cocoons were immersed in 91 of $0.02 \mathrm{M} \mathrm{Na}_{2} \mathrm{CO}_{3}$ solution and boiled at $95 \pm 5^{\circ} \mathrm{C}$ for $120 \mathrm{~min}$. After washing out the sericin residues using completely desalted water, the released fibroin fibers were placed on a supporting-mesh and air-dried for $24 \mathrm{~h}$. Subsequently, the dried fibroin was mixed with Ajisawa's reagent which was composed of $\mathrm{CaCl}_{2}$, ethanol and water $(1: 2: 8)$ at a ratio of $3 \mathrm{~g}$ to $27 \mathrm{ml}$, and kept in a water bath at $78^{\circ} \mathrm{C}$ for $1 \mathrm{~h}$. After cooling down, the dissolved fibroin solution was centrifuged at 4,000 rpm (Rotofix 32, Hettich, Tuttlingen, Germany) for $30 \mathrm{~min}$ to remove debris and undissolved silk. Desalination of the solution was carried out by dialysis against water for two days to reach the final electrical conductivity of less than $15 \mu \mathrm{Scm} / \mathrm{cm}$. The resulting fibroin solution in a concentration of approximately $6 \%$ can either be diluted in distilled $\mathrm{H}_{2} \mathrm{O}$ or concentrated by evaporating ethanol and water at $60-70^{\circ} \mathrm{C}$.

Fibroin solutions of various concentrations of $1.5-15 \%$ were used to produce porous fibroin sponge-like scaffolds using freezethawing. Four $\mathrm{ml}$ of a fibroin solution and $2 \mathrm{ml}$ of $2 \% \mathrm{EtOH}$ were mixed in each well of a 12 -well cell culture plate. The plate was then sealed and placed into a $-20^{\circ} \mathrm{C}$ freezer for $24 \mathrm{~h}$. On the next day, the plate was taken out of the freezer and thawed for one $h$ at room temperature. Fibroin attached to the wall of the well was detached using a scalpel. The freezing-thawing process was repeated three times. The resulting fibroin sponges were carefully removed from the wells and stored in water.

\section{Characterization of the scaffolds}

Electron microscopy. Surface structure of the fibroin scaffolds was evaluated using a scanning electron microscope (Philips XL30 CP, Philips GmbH, Hamburg, Germany). Scaffolds were centrifuged at $500 \mathrm{rpm}$ (Rotofix 32, Hettich, Tuttlingen, Germany) for $60 \mathrm{~min}$ to remove the water. After air-drying for $24 \mathrm{~h}$, samples were sputtered with gold-particles for $90 \mathrm{sec}$ in vacuum $\left(3 \times 10^{-1} \mathrm{bar}\right)$ using argon as carrier gas (Sputter Coater S150B, Edwards, London, UK).

Porosity. A measuring cylinder was filled with $50 \mathrm{ml}$ pure hexane. Hexane penetrates the sponge-like scaffolds without changing the pore structure and without causing swelling or shrinking. For measuring porosity, a sponge was left in the measuring cylinder for $5 \mathrm{~min}$ for the gas to penetrate into the pores. The volume of the hexane was measured before and after taking out the sponge from the measuring cylinder. Porosity in percent was defined as [volume of hexane in the measuring cylinder after filling - residual volume of hexane after taking out the sponge]/[volume of hexane which was displaced by the sponge - residual volume of hexane after taking out the scaffold] $* 100$.

Pressure and stab resistance. The pressure resistance of moist scaffolds was measured for compressive strength and stab-resistance using a Zwick/Roell Z010 XForceK (Zwick GmbH \& Co KG, Ulm, Germany) with an initial force of $0.2 \mathrm{~N}$ and pressing speed of $5 \mathrm{~mm} / \mathrm{min}$. Compressive strength was determined by the pressure module (gradient of the compression). Penetration resistance was measured by the depth

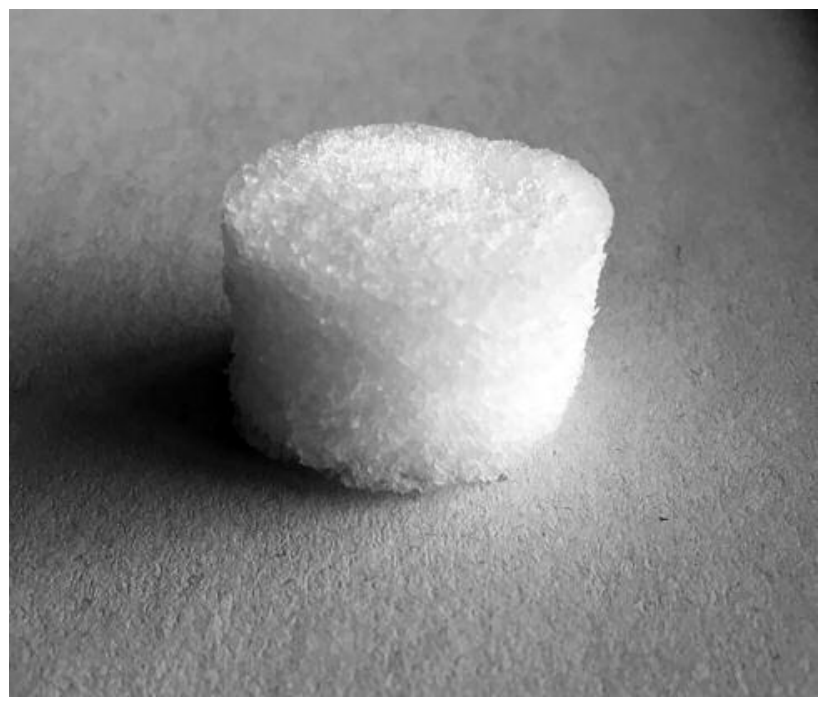

Figure 1. Porous fibroin sponge made after dissolving silk using Ajisawa's reagent and freeze-thawing.

of a needle stabbing into the sponge under a given force. Stabbing speed was set at $0.5 \mathrm{~mm} / \mathrm{min}$ with an initial force of $0.2 \mathrm{~N}$. The gradient was determined by force and penetration depth.

Degradation. Degradation of fibroin scaffolds was examined by placing a test group of 4 scaffolds in a solution of $1 \mathrm{mg} / \mathrm{ml}$ protease $\mathrm{XIV}$ in PBS at $37^{\circ} \mathrm{C}$ in a humified atmosphere of $95 \%$ air and $5 \%$ $\mathrm{CO}_{2}$ for 3 weeks using a HERAcell incubator (HERAcell 150i, Thermo Scientific, Waltham, MA, USA). Four scaffolds placed in PBS without protease XIV were used as a control group. A specially designed probe mount was placed inside the incubator in order to keep the sample flasks in motion during incubation.

\section{Results}

Production of fibroin scaffolds. Cylindrical sponge-like scaffolds were successfully produced from fibroin solutions of various concentrations between 1.5 and $15 \%$ by means of repeated freezing and thawing (Figure 1). Higher concentration of fibroin led to faster sponge formation, likely due to a more pronounced beta-sheet structure and faster crystallization of the protein. Scaffolds from a higher concentration of fibroin solution developed an intensified yellowish color.

Electron microscopy. The surface of the scaffolds was porous (Figure 2). The porosity was subjectively more prominent in the scaffolds of $6 \%$ fibroin solution than in those of $10 \%$ fibroin solution. In scaffolds with reduced fibroin concentration, deep holes were visible, while pores of various forms and sizes interleaved each other, resulting in a complex structure. By contrast, the surface of the $10 \%$ 

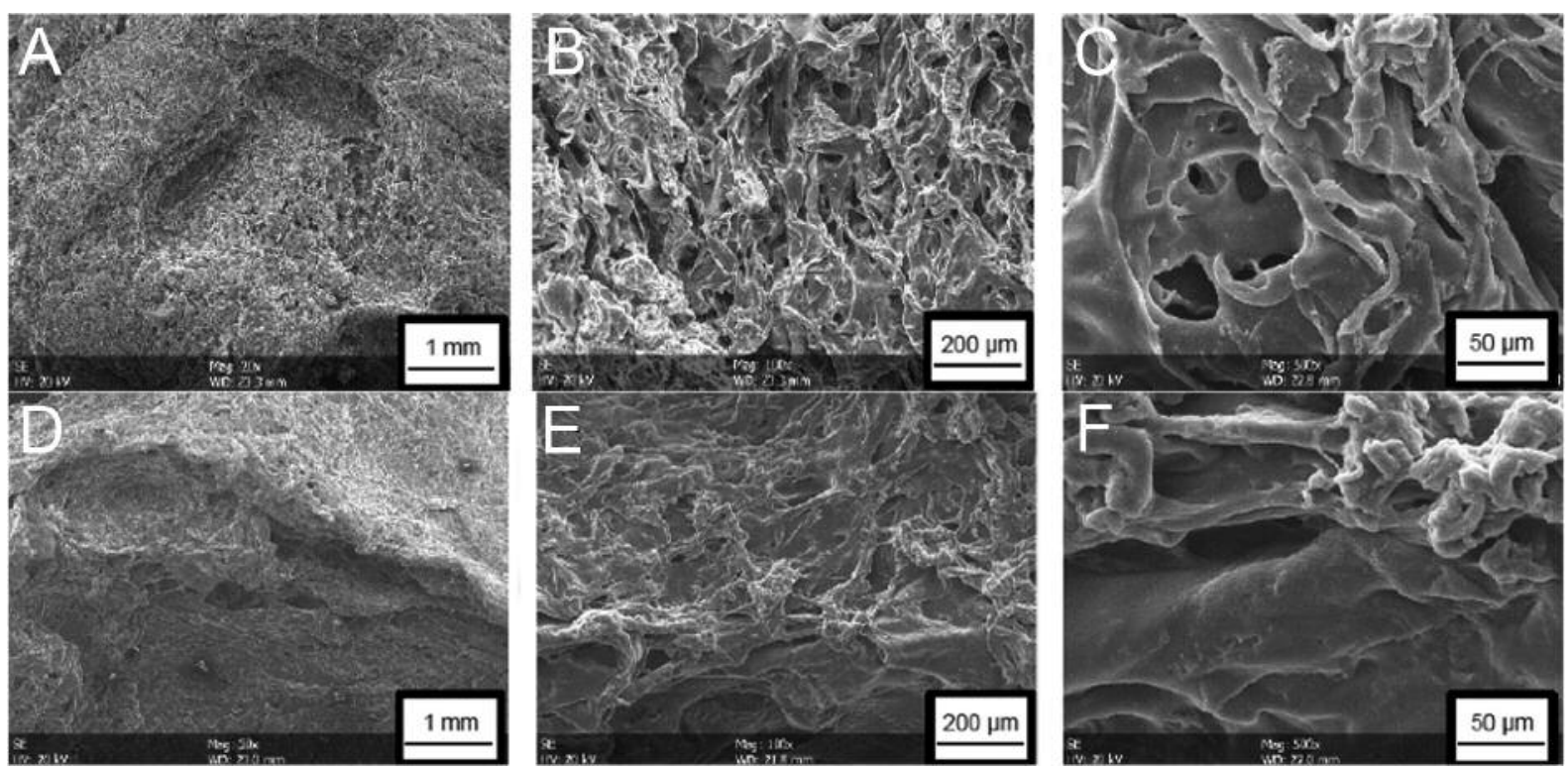

Figure 2. Electron microscopy of the surface structure of the porous fibroin sponges. Upper row, sponge made of 6\% fibroin concentration in solution; lower row, sponge made of $10 \%$ fibroin solution. Magnification $20 \times(A ; D), 100 \times(B ; E)$ and $500 \times(C ; F)$.

fibroin scaffolds appeared rather flat and the beta-sheet formations of the fibroin were more compact. Porous structures were also observed in cross-sections of the scaffolds complying with the expectation that the pores pass through the whole sponge.

Porosity. Porosity measurement, using hexane gas, revealed that pores occupied $50 \% \pm 1.6 \%$ of the volume of a $6 \%$ fibroin sponge. For a $7 \%$ fibroin sponge, the ratio of pore volume to total volume was $10 \%$ less $(40 \% \pm 2.1 \%)$. Prolonged treatment with ethanol led to further crystallization of the fibroin resulting in hardening through enhanced beta-structures of the protein and reduced pore sizes. Subsequently, these ethanol hardened scaffolds were mechanically characterized.

Pressure and penetration resistance. Compressive strength of the scaffolds correlated nearly linearly with the concentration of the initial fibroin solution (Figure 3A) Maximum average compressive strengths of $6.4 \pm 3.7$ and $13.5 \pm 2.2 \mathrm{kPa}$ were measured in the $5 \%$ and $8 \%$ fibroin scaffolds, respectively. The penetration resistance of the scaffolds correlated positively with the initial fibroin concentrations. The mean force-penetration depth ratio was 0.3 and $0.5 \mathrm{~mm} / \mathrm{N}$ for scaffolds from 0.5 and $0.8 \%$ fibroin solutions, respectively (Figure 3B).

Degradation. When incubated in a solution of $1 \mathrm{mg} / \mathrm{ml}$ protease XIV, $4 \%$ fibroin scaffolds were completely digested in 3 weeks. Scaffolds containing 7\% of fibroin lost approximately $83 \%$ of the initial weight after 3 weeks of incubation in protease XIV (Figure 4). In the absence of protease, fibroin scaffolds lost approximately $16 \%$ of their initial weight, regardless of the fibroin concentration.

\section{Discussion}

Many advances in biomaterials science have been made through the past decades (15-17). However, the treatment of extensive defects in soft and hard tissue is still challenging. Silk as biomaterial has been investigated extensively in several studies $(18,19)$. Silk based fibroin scaffolds may be favorable as biomaterial due to their low price, sufficient availability and improved tissue recovery (2). However, conventional manufacturing methods include dissolving in high molarity chaotropic salt solutions such as lithium bromide ( $\mathrm{LiBr}$ ) or ionic liquids (20).

In the present work, an optimized protocol for producing fibroin scaffolds was established. Ajisawa's reagent, which is inexpensive and harmless unlike the conventional reagents, was used to dissolve fibroin from silk fibers. The freeze-thaw method that is a saltless alternative to conventional methods was used to create sponge-like structures in order to use them as scaffolds for medical applications, e.g. in reconstructive medicine $(3,10)$. The resulting scaffolds are, therefore, free of solvent and metal which is a key issue for application in human body.

Three-dimensional structures of fibroin may be favorable in tissue engineering because they can mimic a physiological environment more precisely than two-dimensional structures 


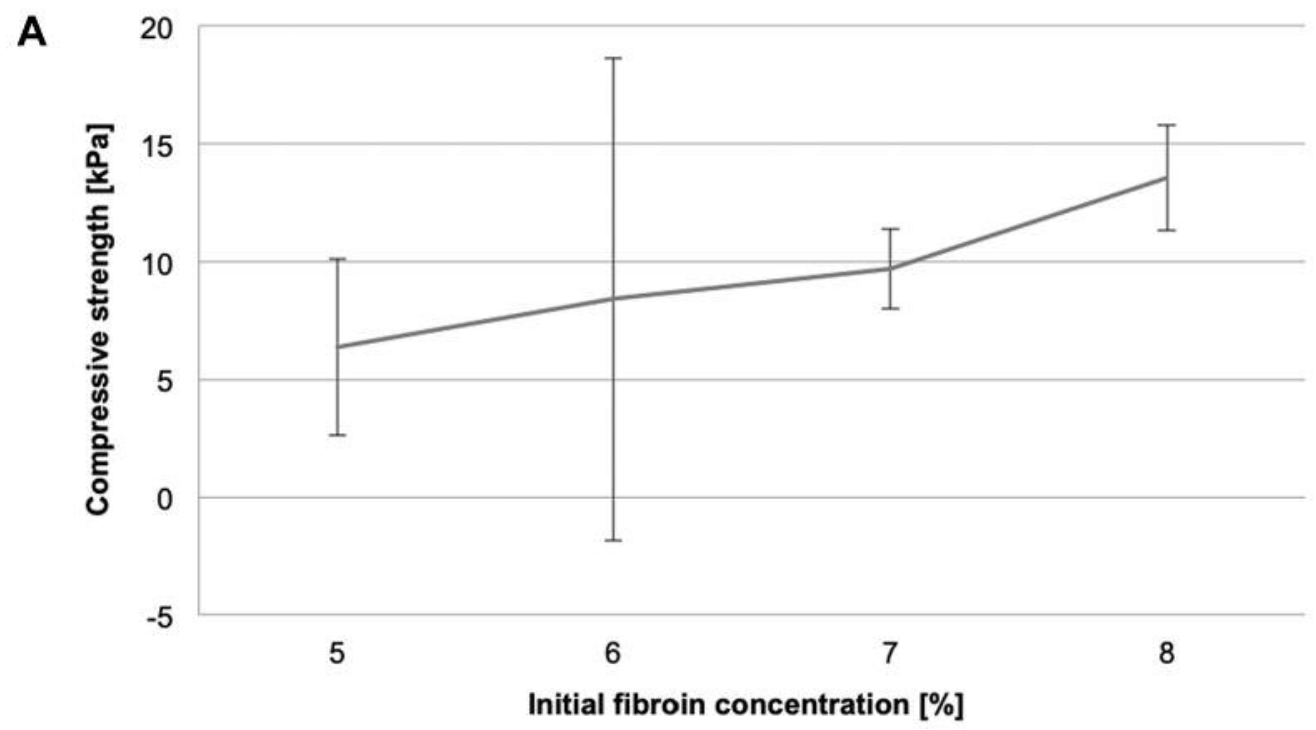

B

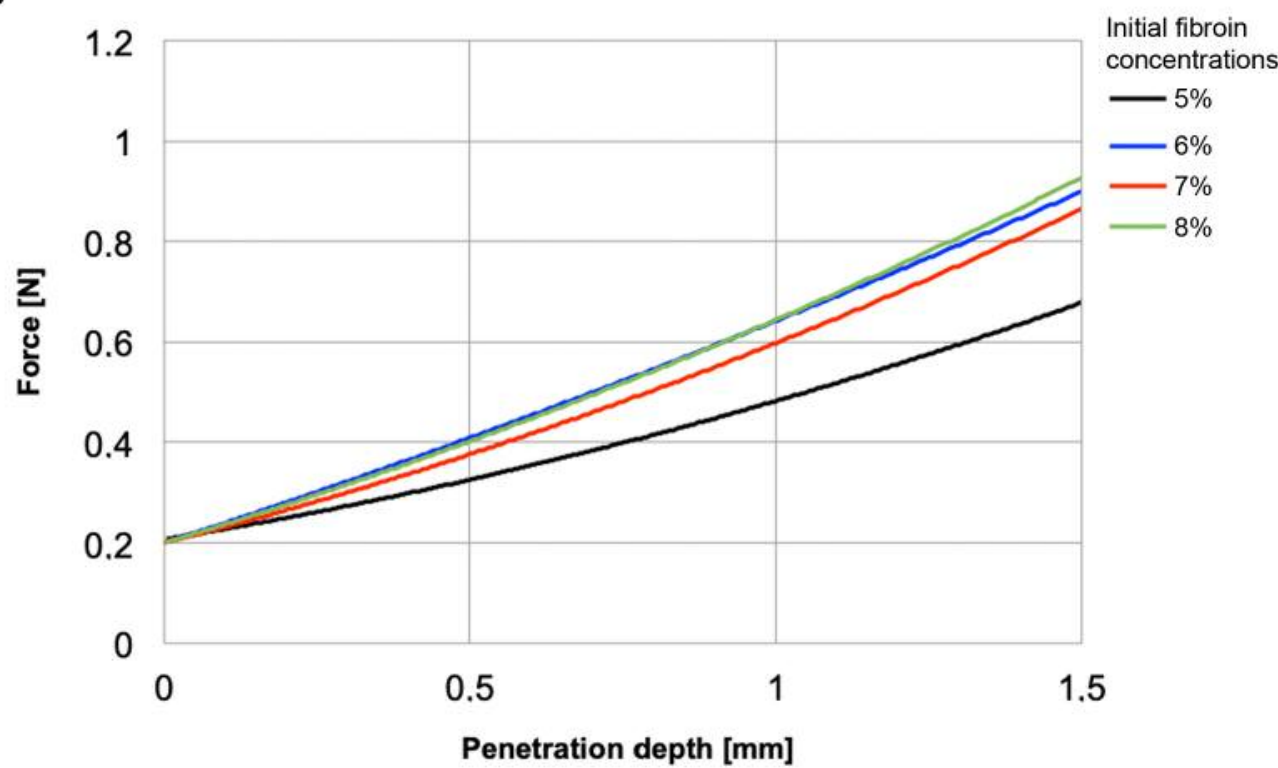

Figure 3. Mechanical characterization of the sponges. A: Compressive strength in correlation with fibroin concentration. B: Penetration resistance.

$(21,22)$. Three-dimensional fibroin scaffolds can be obtained by salt leaching, gas foaming or freeze-thawing (23). Among them, freeze-thawing, which was first described by Tamada, is the simplest and cheapest way to create $3 \mathrm{D}$-fibroin scaffolds (24). Fibroin scaffolds formed by this process are cytocompatible and demonstrate good mechanical characteristics (25). In this study, cylindrical scaffolds were successfully produced from fibroin solutions of various concentrations using the freeze-thaw method after dissolving procedures with Ajisawa's reagent. They displayed high porosity that might be a favorable characteristic for cells. Several studies suggested that interconnected pores within fibroin scaffolds may support cell attachment, proliferation and differentiation $(26,27)$. However, this study only covers the physical characterization of the scaffolds and their behavior in vitro still has to be investigated. Mechanical properties of the created scaffolds correlated positively with the initial fibroin concentration of the solutions. Fibroin scaffolds showed sufficient pressure and penetration resistance that allows their usage as material for tissue engineering. 


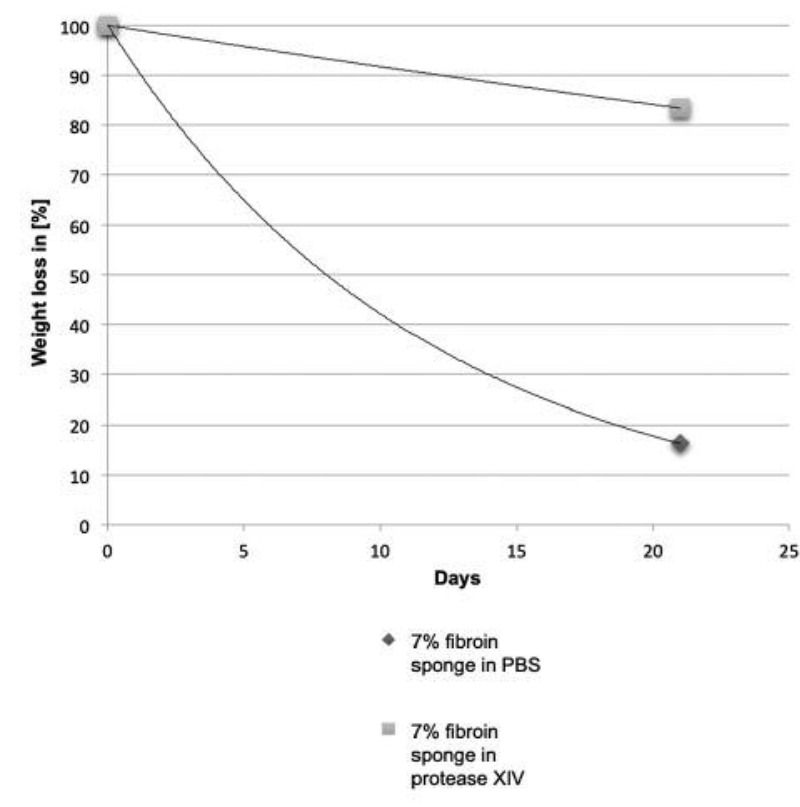

Figure 4. Digestion of 7\% fibroin sponges by protease XIV.

However, the freeze-thaw method has the disadvantage of creating pores of varying sizes, uneven surfaces of the scaffolds, and sticking of the fibroin to the well. The latter problems may be overcome to some extent by using other types of well-plates and non-stick coatings. However, caution has to be taken to ensure that no traces of substances will remain in the final products intended for medical application. Rotating the well-plate during the freeze-thaw process may enable more homogeneous porosity in the scaffolds.

Fibroin concentrations influence many features of the resulting scaffolds, including the structure, porosity, mechanical strength, and degradation behavior (28). Therefore, varying fibroin concentration provides a simple and straightforward strategy for tailoring physical and chemical properties of the fibroin scaffolds for various medical needs. Depending on the tissue of application, for example bone, muscle or fatty tissues, scaffolds with the most suitable pore-size can be produced by selecting the appropriate fibroin concentration. However, the accordance between biodegradation of the scaffolds and growth rate of new tissues has to be considered (29). Three-dimensional bioprinting for layer-by-layer fabrication of objects and scaffolds is one topic of current research (30). A recent study described tissue integration of 3D-printed fibroin-based implants in a mouse model (31). Due to the complexity of 3D-printing procedures, currently only simple structures can be printed. However, as printing techniques advance steadily, the construction of complex and multifunctional structures will be possible in the near future (32).
To conclude, this project has established and optimized a simple procedure for dissolving fibroin and producing porous fibroin scaffolds, which also enables tailoring of their physical and mechanical features for various medical applications. Further studies are in progress to assess cytocompatibility and biocompatibility of the developed fibroin scaffolds.

\section{Conflicts of Interest}

The Authors declare no conflicts of interests and received no financial funding for this study.

\section{Authors' Contributions}

The work presented here was carried out in collaboration between all authors. AK, RS and AH designed the study. SF, MeB and MiB collected and analyzed the data. SF, RR and SB interpreted the data. LK and RF wrote the first draft of the article. AK, RS and MG drafted the article. MG, $\mathrm{RF}$ and $\mathrm{AH}$ revised the article. The research consortium completed the final manuscript. All Authors read and approved the final manuscript.

\section{References}

1 Altman GH, Diaz F, Jakuba C, Calabro T, Horan RL, Chen J, Lu $\mathrm{H}$, Richmond $\mathrm{J}$ and Kaplan DL: Silk-based biomaterials. Biomaterials 24(3): 401-416, 2003. PMID: 12423595.

2 Guan G, Bai L, Zuo B, Li M, Wu Z, Li Y and Wang L: Promoted dermis healing from full-thickness skin defect by porous silk fibroin scaffolds (psfss). Biomed Mater Eng 20(5): 295-308, 2010. PMID: 21084741. DOI: 10.3233/BME-20100643

3 Smeets R, Knabe C, Kolk A, Rheinnecker M, Grobe A, Heiland M, Zehbe R, Sachse M, Grosse-Siestrup C, Woltje M and Hanken $\mathrm{H}$ : Novel silk protein barrier membranes for guided bone regeneration. J Biomed Mater Res B Appl Biomater 105(8): 26032611, 2017. PMID: 27731930. DOI: 10.1002/ jbm.b.33795

4 Smeets R, Vorwig O, Woltje M, Gaudin R, Luebke AM, BeckBroichsitter B, Rheinnecker M, Heiland M, Grupp K, Grobe A and Hanken $\mathrm{H}$ : Microvascular stent anastomosis using n-fibroin stents: Feasibility, ischemia time, and complications. Oral Surg Oral Med Oral Pathol Oral Radiol 121(5): e97-e103, 2016. PMID: 27068318. DOI: 10.1016/j.oooo.2016.01.009

5 Sobajo C, Behzad F, Yuan XF and Bayat A: Silk: A potential medium for tissue engineering. Eplasty 8: e47, 2008. PMID: 18997857.

6 Liu H, Ge Z, Wang Y, Toh SL, Sutthikhum V and Goh JC: Modification of sericin-free silk fibers for ligament tissue engineering application. J Biomed Mater Res B Appl Biomater 82(1): 129-138, 2007. PMID: 17318818. DOI: 10.1002/ jbm.b.30714

7 Lovett ML, Cannizzaro CM, Vunjak-Novakovic G and Kaplan DL: Gel spinning of silk tubes for tissue engineering. Biomaterials 29(35): 4650-4657, 2008. PMID: 18801570. DOI: 10.1016/j.biomaterials.2008.08.025.

8 Lv Q and Feng Q: Preparation of 3-D regenerated fibroin scaffolds with freeze drying method and freeze drying/foaming technique. J Mater Sci Mater Med 17(12): 1349-1356, 2006. PMID: 17143767. DOI: 10.1007/s10856-006-0610-z 
9 Wang HY and Zhang YQ: Processing and characterisation of a novel electropolymerized silk fibroin hydrogel membrane. Sci Rep 4: 6182, 2014. PMID: 25154713. DOI: 10.1038/srep06182

10 Etienne O, Schneider A, Kluge JA, Bellemin-Laponnaz C, Polidori C, Leisk GG, Kaplan DL, Garlick JA and Egles C: Soft tissue augmentation using silk gels: An in vitro and in vivo study. J Periodontol 80(11): 1852-1858, 2009. PMID: 19905955. DOI: 10.1902/jop.2009.090231

11 Bosetti M, Boccafoschi F, Calarco A, Leigheb M, Gatti S, Piffanelli V, Peluso G and Cannas M: Behaviour of human mesenchymal stem cells on a polyelectrolyte-modified hema hydrogel for silk-based ligament tissue engineering. J Biomater Sci Polym Ed 19(9): 1111-1123, 2008. PMID: 18727855. DOI: $10.1163 / 156856208785540145$

12 Frauchiger DA, May RD, Bakirci E, Tekari A, Chan SCW, Woltje M, Benneker LM and Gantenbein B: Genipin-enhanced fibrin hydrogel and novel silk for intervertebral disc repair in a loaded bovine organ culture model. J Funct Biomater 9(3): 2018. PMID: 18727855. DOI: 10.3390/jfb9030040

13 Hanken H, Gohler F, Smeets R, Heiland M, Grobe A, Friedrich RE, Busch P, Blessmann M, Kluwe L and Hartjen P: Attachment, viability and adipodifferentiation of pre-adipose cells on silk scaffolds with and without co-expressed FGF-2 and VEGF. In Vivo 30(5): 567-572, 2016. PMID: 27566073.

14 Saran K, Shi P, Ranjan S, Goh JC and Zhang Y: A moldable putty containing silk fibroin yolk shell particles for improved hemostasis and bone repair. Adv Healthc Mater 4(3): 432-445, 2015. PMID: 25296961. DOI: 10.1002/adhm.201400411

15 Hartjen P, Hoffmann A, Henningsen A, Barbeck M, Kopp A, Kluwe L, Precht C, Quatela O, Gaudin R, Heiland M, Friedrich RE, Knipfer C, Grubeanu D, Smeets R and Jung O: Plasma electrolytic oxidation of titanium implant surfaces: Microgroovestructures improve cellular adhesion and viability. In Vivo 32(2): 241-247, 2018. PMID: 29475905. DOI: 10.21873/invivo.11230

16 Hartjen P, Nada O, Silva TG, Precht C, Henningsen A, Holthaus MG, Gulow N, Friedrich RE, Hanken H, Heiland M, Zwahr C, Smeets $\mathrm{R}$ and Jung $\mathrm{O}$ : Cytocompatibility of direct laser interference-patterned titanium surfaces for implants. In Vivo 31(5): 849-854, 2017. PMID: 28882950.

17 Vollkommer T, Henningsen A, Friedrich RE, Felthaus OH, Eder F, Morsczeck C, Smeets R, Gehmert S and Gosau M: Extent of inflammation and foreign body reaction to porous polyethylene in vitro and in vivo. In Vivo 33(2): 337-347, 2019. PMID: 30804110. DOI: 10.21873 /invivo.11479

18 Cao Y and Wang B: Biodegradation of silk biomaterials. Int J Mol Sci 10(4): 1514-1524, 2009. PMID: 19468322. DOI: $10.3390 / \mathrm{ijms} 10041514$

19 Guan G, Wang L, Li M and Bai L: In vivo biodegradation of porous silk fibroin films implanted beneath the skin and muscle of the rat. Biomed Mater Eng 24(1): 789-797, 2014. PMID: 24211965. DOI: 10.3233/BME-130870

20 Qi Y, Wang H, Wei K, Yang Y, Zheng RY, Kim IS and Zhang KQ: A review of structure construction of silk fibroin biomaterials from single structures to multi-level structures. Int J Mol Sci 18(3): 2017. PMID: 28273799. DOI: 10.3390/ijms 18030237
21 Lutolf MP, Gilbert PM and Blau HM: Designing materials to direct stem-cell fate. Nature 462(7272): 433-441, 2009. PMID: 19940913. DOI: 10.1038 /nature08602

22 Jung O, Hanken H, Smeets R, Hartjen P, Friedrich RE, Schwab B, Grobe A, Heiland M, Al-Dam A, Eichhorn W, Sehner S, Kolk A, Woltje $M$ and Stein JM: Osteogenic differentiation of mesenchymal stem cells in fibrin-hydroxyapatite matrix in a 3dimensional mesh scaffold. In Vivo 28(4): 477-482, 2014. PMID: 24982212.

23 Nazarov R, Jin HJ and Kaplan DL: Porous 3-D scaffolds from regenerated silk fibroin. Biomacromolecules 5(3): 718-726, 2004. PMID: 15132652. DOI: 10.1021/bm034327e

24 Tamada Y: New process to form a silk fibroin porous 3-D structure. Biomacromolecules 6(6): 3100-3106, 2005. PMID: 16283733. DOI: $10.1021 / \mathrm{bm} 050431 \mathrm{f}$

25 Nourmohammadi J, Roshanfar F, Farokhi M and Haghbin Nazarpak M: Silk fibroin/kappa-carrageenan composite scaffolds with enhanced biomimetic mineralization for bone regeneration applications. Mater Sci Eng C Mater Biol Appl 76: 951-958, 2017. PMID: 28482612. DOI: 10.1016/j.msec.2017.03.166

26 Mandal BB and Kundu SC: Cell proliferation and migration in silk fibroin 3D scaffolds. Biomaterials 30(15): 2956-2965, 2009. PMID: 19249094. DOI: 10.1016/j.biomaterials.2009.02.006

27 Ribeiro M, de Moraes MA, Beppu MM, Garcia MP, Fernandes MH, Monteiro FJ and Ferraz MP: Development of silk fibroin/nanohydroxyapatite composite hydrogels for bone tissue engineering. Eur Polym J 67: 66-77, 2015. DOI: 10.1016/ j.eurpolymj.2015.03.056

28 Koh LD, Cheng Y, Teng CP, Khin YW, Loh XJ, Tee SY, Low M, Ye E, Yu HD, Zhang YW and Han MY: Structures, mechanical properties and applications of silk fibroin materials. Prog Polym Sci 46: 86-110, 2015. DOI: 10.1016/j.progpolymsci.2015.02.001

29 Boyd M, Flasza M, Johnson PA, Roberts JS and Kemp P: Integration and persistence of an investigational human living skin equivalent (icx-skn) in human surgical wounds. Regen Med 2(4): 363-370, 2007. PMID: 17608606. DOI: 10.2217/17 460751.2.4.363

30 Murphy SV and Atala A: 3D bioprinting of tissues and organs. Nat Biotechnol 32(8): 773-785, 2014. PMID: 25093879. DOI: 10.1038/nbt.2958

31 Rodriguez MJ, Brown J, Giordano J, Lin SJ, Omenetto FG and Kaplan DL: Silk based bioinks for soft tissue reconstruction using 3-dimensional (3D) printing with in vitro and in vivo assessments. Biomaterials 117: 105-115, 2017. PMID: 27940389. DOI: 10.1016/j.biomaterials.2016.11.046

32 Wang Q, Han G, Yan S and Zhang Q: 3D printing of silk fibroin for biomedical applications. Materials (Basel) 12(3): 2019. PMID: 30736388. DOI: 10.3390/ma12030504

Received March 7, 2019

Revised April 2, 2019

Accepted April 3, 2019 